\title{
Graphenes, One of the Hottest Areas in the Nanotechnology: Attention of Chemists is Needed
}

\author{
Oxana V. Kharissova and Boris I. Kharisov* \\ Universidad Autónoma de Nuevo León, Monterrey, México
}

\begin{abstract}
Synthesis, structure, properties, main reactions, and applications of graphenes are reviewed. It is shown that these compounds possess unique properties, which can be successfully used for a series of applications, mainly as nanodevices and composite materials.
\end{abstract}

Keywords: Graphenes, graphite, thin films, carbon, nanoelectronics.

\section{INTRODUCTION}

Carbon is one of the most interesting elements in the Periodic Table. It forms a series of allotropes, some of them are known from thousands of years (3D diamond and 2D graphite) and other discovered 10-20 years ago (0D fullerenes and 1D carbon nanotubes). Its new allotropic form, 2D graphene \{nanographenes are also known as polycyclic aromatic hydrocarbons (PAHs) , discovered in 2004, is a rapidly rising star on the horizon of materials science and condensedmatter physics. This strictly two-dimensional material exhibits exceptionally high crystal and electronic quality, and, despite its short history, has already revealed a cornucopia of new physics and potential applications, which are briefly discussed here. Graphene represents a conceptually new class of materials that are only one atom thick (it is just one layer of carbon atoms [1], a similar structure to graphite but is a single isolated sheet of carbon), and, on this basis, offers new inroads into low-dimensional physics that has never ceased to surprise and continues to provide a fertile ground for applications [2]. Strictly 2D crystals, such as planar graphene, have for long time been considered as a thermodinamically unstable form with respect to the formation of curved structures such as fullerenes or nanotubes. Geim \& Novoselov described [2] that small size $(<<1 \mathrm{~mm})$ and strong interatomic bonds ensure that thermal fluctuations cannot lead to the generation of dislocations or other crystal defects even at elevated temperature. The extracted 2D crystals become intrinsically stable by gentle crumpling in the third dimension; such 3D warping (observed on a lateral scale of $\approx 10 \mathrm{~nm}$ ) leads to a gain in elastic energy but suppresses thermal vibrations (anomalously large in 2D), which above a certain temperature can minimize the total free energy [2] and ref. therein.

Despite the fact that graphene was discovered recently, its structure, properties and applications have already been generalized in a series of monographs [3-6] and reviews [710] (among which we note an excellent work of Mullen on graphenes as potential material for electronics [11]). Various patents are dedicated to obtaining graphenes [12-14]. Among experimental works, we note a number of investigations of

*Address correspondence to these authors at the Universidad Autónoma de Nuevo León, Monterrey, México; E-mail: bkhariss@mail.ru
Novoselov [15-19] who precisely discovered this material. At present, graphene area is one of the hottest topics in physics and nanotechnology [20].

\section{STRUCTURE AND PROPERTIES}

Graphene is a layer of carbon atoms, connected in a hexagonal two-dimensional crystalline lattice, i.e. a plane, consisting of hexagonal cells (Fig. 1). It can be considered as one graphite plane, separated from the voluminous crystal. Two atoms A and B are situated in an elementary cell of the crystal. Each one, at a displacement on the translation vectors forms sub-lattice from the atoms, equivalent to it, i.e. crystal properties are non-dependent on observation points, situated in the equivalent places of the crystal. The distance between the closest carbon atoms in graphene $\mathrm{a}_{0}$ is $0,142 \mathrm{~nm}$ (Fig. 2).

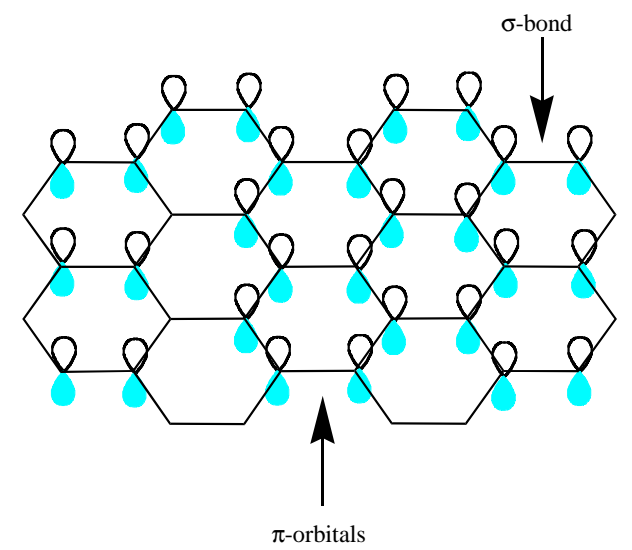

Fig. (1). Structure of graphene.

An ideal graphene consists exclusively of hexagonal cells. Presence of penta- or heptagonal cells leads to various types of defects [21]. Appearance of pentagonal cells leads to a turning of the atomic plane to a cone. Examining 12 such defects simultaneously, the fullerene structure is formed. Presence of heptagonal cells leads to the formation of saddle-type distortions of the atomic plane. Combinations of these defects and normal cells could lead to the formation of distinct surface forms. Additional data of graphene forms is given in [22-24]. A series of two-dimensional sheets of hexagonal carbon rings, with hydrogens around the edges, has been investigated computationally as models for graphene [25]. 


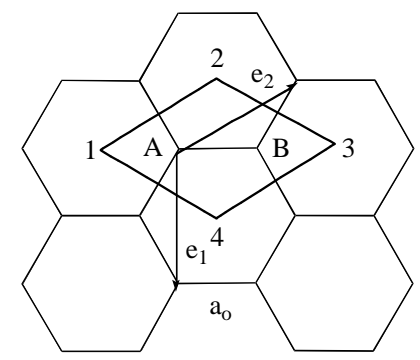

Fig. (2). Hexagonal cell of graphene. $e_{1}$ and $e_{2}$ are translation vectors; the rhomb 1234 is the elemental cell.

There are a series of graphene derivatives reported; the basic ones are presented in [26]: $\mathrm{C}_{62} \mathrm{H}_{20}$ (a 'flake' of graphite with hydrogen used to terminate the dangling bonds), graphene with adatom $\mathrm{C}_{63} \mathrm{H}_{20}$ (a two-fold coordinated additional carbon atom on a graphene sheet; represents one of the stable structures of a carbon interstitial on graphite), graphene with adatom pair $\mathrm{C}_{64} \mathrm{H}_{20}$ (two additional carbon atoms on a graphene sheet (represents an interstitial pair on the surface of graphite), and graphene with $\mathrm{CO}_{3}$ molecule. One important example is $D_{6 h}$ symmetric hexa-peri-hexabenzocoronene (HBC, "super-benzene", Fig. 3a), containing 42 carbon atoms, its symmetric and asymmetric derivatives with a variety of functional groups (Fig. 3b,c), and oligomers (Fig. 4).
A series of distinct larger graphenes, containing 90, 96, 132,150 , and 222 carbon atoms in their cores and different substituents, is reviewed in [11]; some of them are as follows (Fig. 5):

Number of graphene layers (sheets) is an important magnitude, which can be exactly counted by various methods. One of them is based on the quantitative analysis of electron diffraction intensity and allows detection of a single graphene sheet in a carbon nanofilm [27]. In another report [28], the single-, bilayer-, and multiple-layer graphene $(<10$ layers) are clearly discriminated on Si substrate with a $285 \mathrm{~nm}$ $\mathrm{SiO}_{2}$ capping layer by using contrast spectra, which were generated from the reflection light of a white light source. Two easy-to-use methods to determine the number of graphene layers based on contrast spectra are provided: a graphic method and an analytical method. The authors mention that the refractive index of graphene is different from that of graphite. Graphene and graphene layers were investigated on different substrates by monochromatic and whitelight confocal Rayleigh scattering microscopy [29]. It was established that for a few layers $(<6)$, the monochromatic contrast increases linearly with thickness. Rayleigh imaging is a general, simple, and quick tool to identify graphene layers, which is readily combined with Raman scattering, that provides structural identification. The intershell and interlayer interaction (complexation) energies of graphene

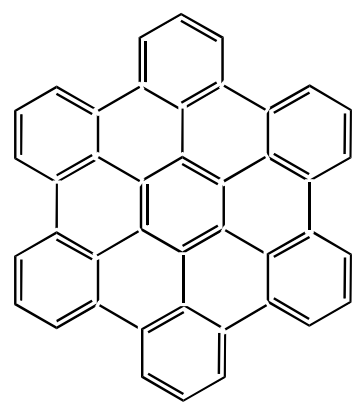

a

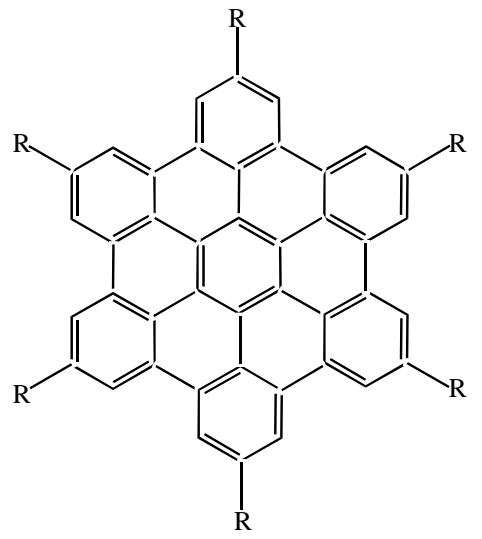

b

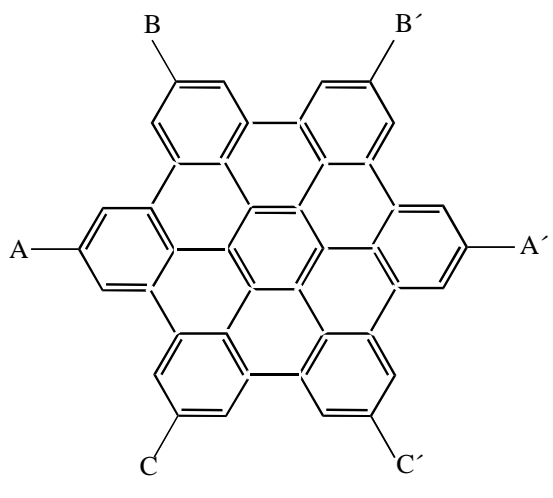

c

Fig. (3). a Hexa-peri-hexabenzocoronene, $\mathbf{b}$ and $\mathbf{c}$ - its symmetric and asymmetric derivatives, respectively.

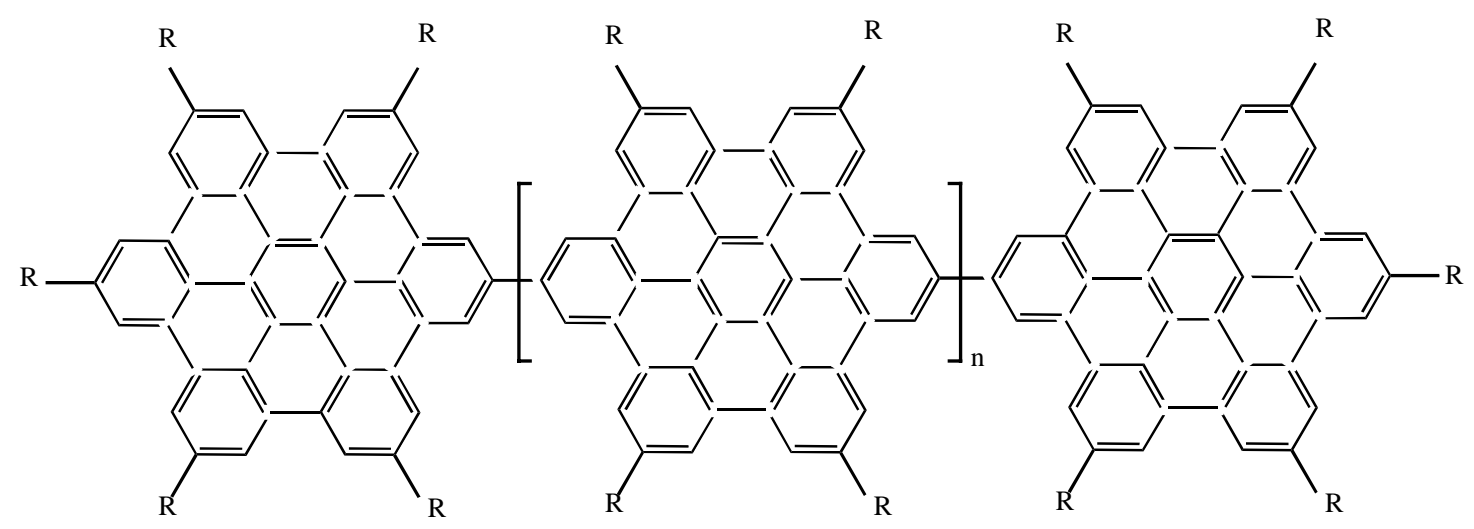

Fig. (4). HBC oligomers. 


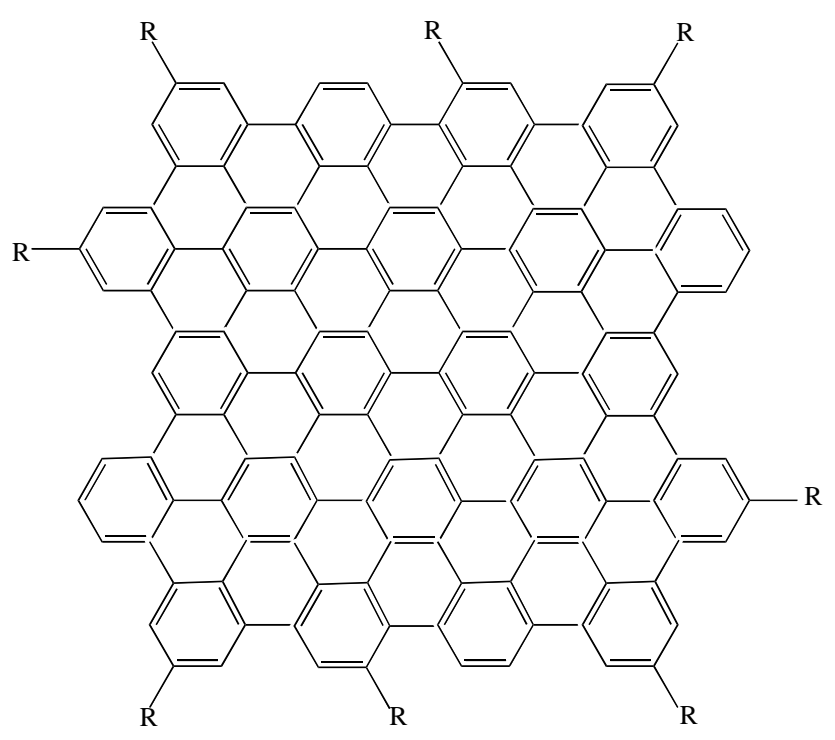

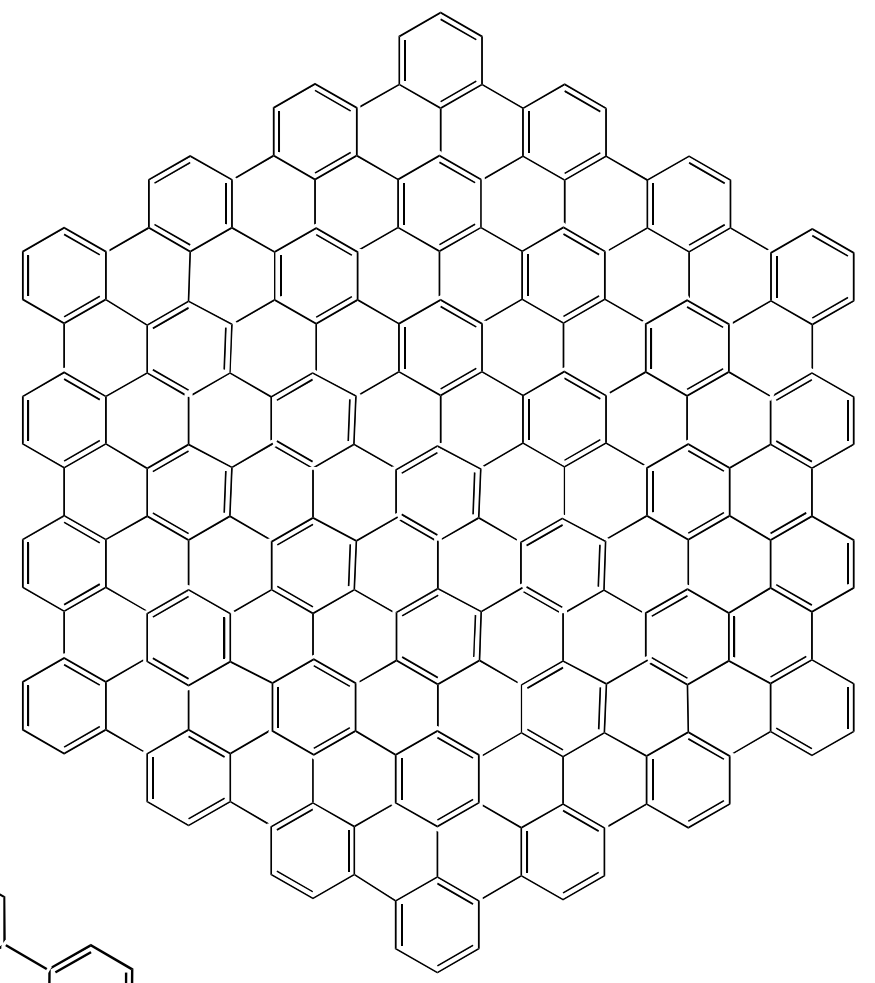

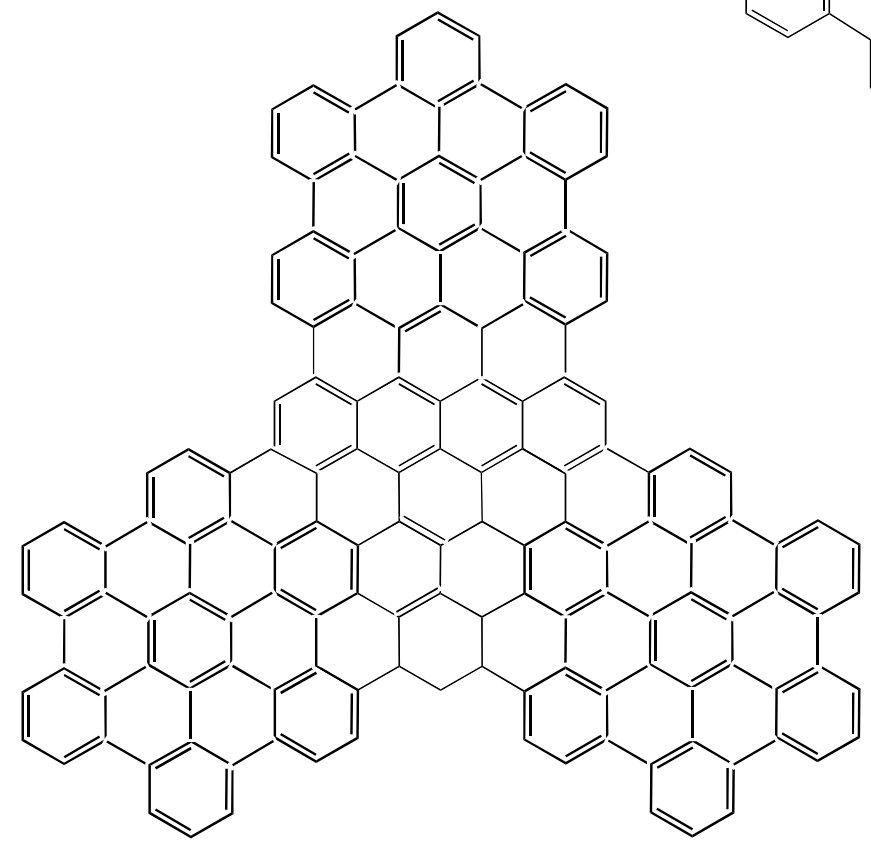

Fig. (5). Larger graphenes.

sheets are investigated by all-electron density functional theory (DFT) using generalized gradient approximation (GGA) functionals and an empirical correction for dispersion (van der Waals) effects (DFT-D method) [30]. The theoretical approach is first applied to graphene sheet model dimers of increasing size $\left\{\right.$ up to $\left(\mathrm{C}_{216} \mathrm{H}_{36}\right)_{2}$ \}. The interaction energies are extrapolated to infinite lateral size of the sheets. The value of $-66 \mathrm{meV} /$ atom obtained for the interaction energy of two sheets supports the most recent experimental estimate for the exfoliation energy of graphite $(-52 \pm 5 \mathrm{meV} /$ atom $)$. The interlayer equilibrium distance $(334 \pm 3 \mathrm{pm})$ is also obtained accurately.

One of the most frequently reported graphene materials is a graphene sheet supported by an insulating silicon dioxide substrate; its properties are intensively studied. Thus, scanning probe microscopy was employed to reveal atomic structures and nanoscale morphology of graphene-based electronic devices [31]. Atomic resolution scanning tunneling microscopy images reveal the presence of a strong spatially dependent perturbation, which breaks the hexagonal lattice symmetry of the graphitic lattice. A novel cleaning process to produce atomically clean graphene sheets was offered.

Electronic properties of graphenes are described in a series of publications [32-35]. Electrons in graphene, obeying a linear dispersion relation, behave like massless relativistic particles or quantum billiard balls. This results in the observation of a number of very peculiar electronic properties - from an anomalous quantum Hall effect to the absence 
of localization - in this, the first two-dimensional material. It also provides a bridge between condensed matter physics and quantum electrodynamics, and opens new perspectives for carbon-based electronics [36]. Electrons in bilayer graphene possess an unusual property: they are chiral quasiparticles characterized by Berry phase $2 \pi$. Researchers at The University of Manchester have just found that electrons move more easily in graphene than all other materials, including gold, silicon, gallium arsenide and carbon nanotubes [37] and have singled graphene out as the "best possible" material for electronic applications. With a high electronic quality - measured at around $200,000 \mathrm{~cm}^{2} / \mathrm{Vs}$ and more than 100 times higher than for silicon - these researchers believe graphene has the potential to improve upon the capabilities of current semiconductors and open up exciting new possibilities.

The tight-binding model of bilayer graphene which determines the band structure and low-energy quasiparticle properties of this material is reviewed in [38]. A comprehensive theoretical study of the electronic properties and relative stabilities of edge-oxidized zigzag graphene nanoribbons is presented in [39]. The oxidation schemes considered include hydroxyl, lactone, ketone, and ether groups. Using screened exchange density functional theory, it was shown that these oxidized ribbons are more stable than hydrogen-terminated nanoribbons except for the case of the etheric groups. Electronic transport properties of individual chemically reduced graphene oxide sheets is reported in [40].

Magnetic properties of arbitrarily shaped finite graphene fragments \{referred by authors as graphene nanoflakes (GNFs) \} were investigated using benzenoid graph theory and first-principles calculations [41]. It was demonstrated that the spin of a GNF depends on its shape due to topological frustration of the $\pi$-bonds. In general, the principle of topological frustration can be used to introduce large net spin and interesting spin distributions in graphene. In another report [42], it was found that an antiferromagnetic (AFM) phase appears as the PAH reaches a certain size. This AFM phase in PAHs has the same origin as the one in infinitely long zigzag-edged graphene nanoribbons, namely, from the localized electronic state at the zigzag edge. The smallest PAH still having an AFM ground state is identified. Magnetism in graphene nanoislands is examined in [43].

Solution properties of graphite are reported in [44]. It was suggested that solutions of functionalized oxidized graphite in common organic solvents consist of single and few layer graphene sheets. Soluble graphene layers were also formed by reacting graphite fluoride with alkyl lithium reagents [45]. Covalent attachment of alkyl chains to the graphene layers was confirmed. It was revealed that the chemical process partially restores the $\mathrm{sp}^{2}$ carbon network. A onestep chemical treatment of graphite fluoride allows the manipulation of a soluble form of graphene.

Optical properties of armchair-edged graphene nanoribbons (AGNRs) with many-electron effects included are reported in [46]. The characteristics of the excitons of the three distinct families of AGNRs are compared and discussed. The enhanced excitonic effects found here are expected to be of importance in optoelectronic applications of graphene-based nanostructures. A simple optical method is presented for identifying and measuring the effective optical properties of nanometer-thick, graphene-based materials, based on the use of substrates consisting of a thin dielectric layer on silicon [47]. The effective refractive index and optical absorption coefficient of graphene oxide, thermally reduced graphene oxide, and graphene are obtained by comparing the predicted and measured contrasts.

Raman spectroscopy measurements of graphenes are reported in a number of reports [48-50]. The authors of [51] investigated the influence of substrates $\{\mathrm{GaAs}$, sapphire, glass and standard $\mathrm{Si} / \mathrm{SiO}_{2}(300 \mathrm{~nm}$, served as a reference) substrates $\}$ on Raman scattering spectrum from graphene. It was found that while $G$ peak of graphene on $\mathrm{Si} / \mathrm{SiO}_{2}$ and

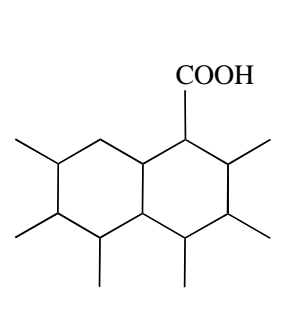

Carboxyl<smiles>C=C1OC(=O)C2C(C)C(C)C(C)C3C(C)C(C)C(C)C1C23</smiles>

Carboxylic anhydride<smiles>CC1C(C)C2C(=O)OC3C(C)C(C)C(C1C)C32</smiles>

Lactone<smiles>CC1CC2C3CC(C)C(C)C(C)C3C(=O)C(=O)C2C(C)C1C</smiles>

Quinone<smiles>CC1CC2C(O)C(C)C(C)C(C)C2C(C)C1C</smiles>

Hydroxyl<smiles>CC1CC2C(=O)C(C)C(C)C(C)C2C(C)C1C</smiles>

Carbonyl<smiles>C=C1OC2(O)C(C)C(C)C(C)C3C(C)C(C)C(C)C1C32</smiles>

Lactol<smiles>CC1CC2OC(C)C(C)C(C)C2C(C)C1C</smiles>

Ether

Fig. (6). Surface oxygen groups on graphite. 
GaAs is positioned at $1580 \mathrm{~cm}^{-1}$, it is downshifted by $\sim 5$ $\mathrm{cm}^{-1}$ for graphene on sapphire and, in some cases, splits into doublets for graphene on glass with the central frequency around $1580 \mathrm{~cm}^{-1}$.

Capacitance-voltage $(C-V)$ characteristics are important for understanding fundamental electronic structures and device applications of nanomaterials. The $C-V$ characteristics of graphene nanoribbons (GNRs) are examined using selfconsistent atomistic simulations. The results indicate strong dependence of the GNR $C$ - $V$ characteristics on the edge shape [52]. Graphene nanoribbons are also examined in [5358]. It is noted that all graphene nanoribbons are semiconductors and they have possible applications to future quantum device. The zigzag edge of a graphene nanoribbon possesses a unique electronic state that is near the Fermi level and localized at the edge carbon atoms [59]. The chemical reactivity of these zigzag edge sites was elucidated by examining their reaction energetics with common radicals from first principles. Among other studies of this form of carbon, plasma waves in graphenes are reported in $[60,61]$.

\section{SYNTHESIS}

The principal method for graphene production [62] is based on the mechanical exfoliation of graphite layers by micromechanical cleavage, allowing obtaining high-quality samples. Thin graphite layers are put between sticky tapes and remove thin graphite layers to get a sufficiently thin layer. Then the sample is collocated on the support of $\mathrm{SiO}_{2}$. AFM studies are used for determining real thickness of the graphene film ( 0.35 to $0.8 \mathrm{~nm})$.

Graphenes are also produced by a series of other methods, in particular by CVD/pyrolisis techniques as simple, economical and reproducible method. Thus, planer few layer graphenes films were synthesized from camphor pyrolysis on nickel substrates by simple, cost effective thermal CVD

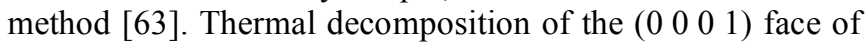
a $6 \mathrm{H}-\mathrm{SiC}$ wafer, demonstrated the successful growth of single crystalline films down to approximately one graphene layer [64]. Three-step process for producing nano-scaled graphene plate material is reported in [65]. It includes carbonizing a polymer or heat-treating petroleum or coal tar pitch, producing micron- and/or nanometer-scaled graphite crystallites, exfoliating the graphite crystallites in the polymeric carbon and subjecting the polymeric carbon containing exfoliated graphite crystallites to a mechanical attrition treatment.

Graphene films can be obtained on various supports. Thus, the synthesis of bilayer graphene thin films deposited on insulating silicon carbide is reported in [66-68]. Formed bilayer graphene can potentially possess switching functions in atomic-scale electronic devices. It is shown [69] that graphenes grown from the $\mathrm{SiC}(0001)$ (C-terminated) surface are of higher quality than those previously grown on $\mathrm{SiC}(0001)$. Graphene grown on the $\mathrm{C}$ face can have structural domain sizes more than three times larger than those grown on the $\mathrm{Si}$ face while at the same time reducing $\mathrm{SiC}$ substrate disorder from sublimation by an order of magnitude. As it was noted [70], despite the thickness of graphite layer is more than one monolayer, only the closest layer to the supporting surface takes part in conductivity, since a non-compensated charge is formed in the border SiC-C due to the differences of works of an output of two materials.

Graphite platelets of $1-5 \mu \mathrm{m}$ in diameter consisting of a few graphenes were generated from commercially available exfoliated graphite by ultrasonic treatment in benzene $(1 \mathrm{mg}$ material in $20 \mathrm{ml}$ solvent) for $3 \mathrm{~h}$. Successive oxidation of the sample was carried out at $450-550{ }^{\circ} \mathrm{C}$ in air. AFM measurements showed that the thermal oxidation removed 2-3 graphenes from the platelets and it left behind single graphene layers [71].

Chemical techniques are also used for obtaining nanometric graphene layers. Thus [44], graphite microcrystals are treated with a mixture of $\mathrm{HCl}$ and $\mathrm{H}_{2} \mathrm{SO}_{4}$, forming carboxyl groups in the sample edges (Fig. 6). Then they are transformed into chlorides using $\mathrm{SOCl}_{2}$ and graphene layers by action of octadecylamine in organic solvents. Novel tubein-tube nanostructures are similarly obtained in [72]. Small

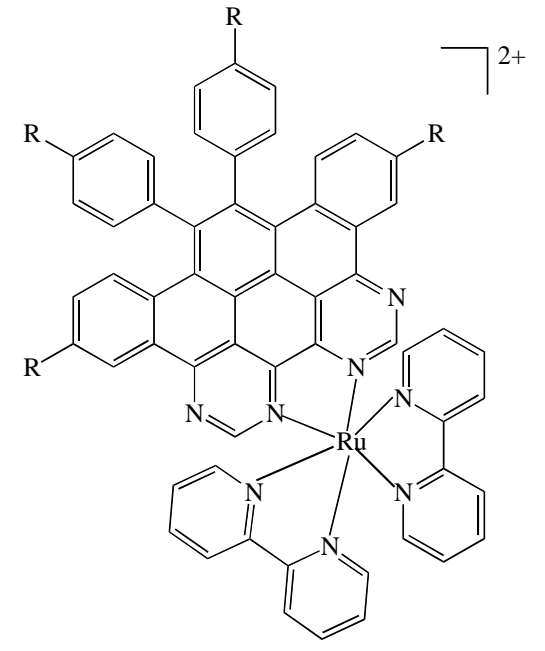

a

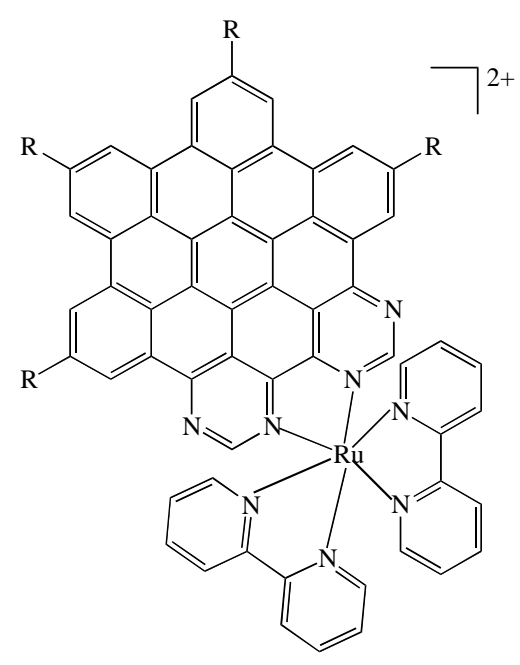

b

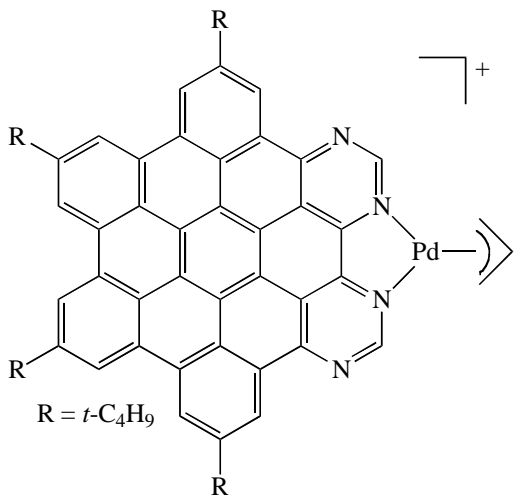

c

Fig. (7). a,b) Ruthenium- and c) palladium-graphene complexes. 
graphene sheets were produced by disintegration of the graphitic nanoparticles via an intercalation-exfoliation process with nitric acid, during which the graphene sheets were simultaneously modified with carboxyl and hydroxyl groups at their edges. Reduction of a colloidal suspension of exfoliated graphene oxide sheets in water with hydrazine hydrate results in their aggregation and subsequent formation of a high-surface-area carbon material which consists of thin graphene-based sheets [73]. A comprehensive generalization of techniques for obtaining various, in particular larger graphenes is given in [11].

The inclusion of heteroatoms into the graphene molecules offers the possibility of making novel PAH-based metal complexes. In case of nitrogen as a heteroatom, oxidative cyclodehydrogenation is an important process in the formation of the new graphene of the "half-cyclized" nitrogen-heterosuperbenzene $\mathrm{N}-1 /{ }_{2} \mathrm{HSB}$ [74]. This heteropolyaromatic results from the $\mathrm{FeCl}_{3}$-catalyzed oxidative cyclodehydrogenation of 1,2-dipyrimidyl-3,4,5,6-tetra-(4-tertbutylphenyl)benzene. Three new $\mathrm{C}-\mathrm{C}$ bonds are formed that lock the two pyrimidines in a molecular platform comprising eight fused aromatic rings flanked by two remaining "uncyclized" phenyl rings. Heteroleptic Ru(II) complexes, $\left[\mathrm{Ru}(\mathrm{bpy})_{2}\left(\mathrm{~N}-{ }^{1}{ }_{2} \mathrm{HSB}\right)\right]\left(\mathrm{PF}_{6}\right)_{2}$ and $\left[\mathrm{Ru}(\mathrm{bpy})_{2}(\mathrm{~N}-\mathrm{HSB})\right]\left(\mathrm{PF}_{6}\right)_{2}$, which differ in the size and planarity of their aromatic ligands, were also obtained (Fig. 7a,b). Palladium(II) complex $\quad\left[\mathrm{Pd}\left(\eta^{3}-\mathrm{C}_{3} \mathrm{H}_{5}\right)\right.$ (tetra-peri-(tert-butyl-benzo)-di-peri(pyrimidino)-coronene) $\mathrm{PF}_{6}$ ] is also known (Fig. 7c) [75].

Oxidation of graphite produces graphite oxide (GO, Fig. 8-9), which is dispersible in water as individual platelets. After deposition onto $\mathrm{Si} / \mathrm{SiO}_{2}$ substrates, its chemical reduction produces graphene sheets. Electrical conductivity measurements indicate a 10000-fold increase in conductivity after chemical reduction to graphene [76]. The thermal expansion mechanism of graphite oxide to produce functionalized graphene sheets is provided [77]. After dispersion by ultrasonication in appropriate solvents, statistical analysis by atomic force microscopy shows that $80 \%$ of the observed flakes are single sheets. Thermal exfoliation of graphite oxide can produce single sheets of functionalized graphene [78]. Although graphite oxide is an insulator, functionalized graphene produced by this method is electrically conducting. A number of functionalized graphite oxides were prepared by treatment of graphite oxide with organic isocyanates [79]. These isocyanate-treated GOs (iGOs) can then be exfoliated into functionalized graphene oxide nanoplatelets that can form a stable dispersion in polar aprotic solvents. Another route to graphenes through intercalated graphite is reported in [80] (Fig. 10). It includes subsequent treatment of graphite with potassium, EtOH and further exfoliation and sonication, leading to carbon nanoscrolls through graphene sheets [81].

A straightforward technique using electrostatic attraction is demonstrated to transfer graphene sheets, one to a few atomic layers thick, to a selected substrate. Graphite crystal was collocated between electrodes; graphite pieces, including thin films, can move to $\mathrm{SiO}_{2}$ support due to the electric field. Sheets from one to 22 layers thick have been transferred by this method [84]. Applied voltage was $1-13 \mathrm{kV}$.

Mechanisms of graphene formation and growth are examined in [85]. A reaction pathway for growth is explored in which two cyclopenta-carbon groups combine on the zigzag edge of a graphene layer [86]. The process is initiated by $\mathrm{H}$ addition to a five-membered ring, followed by opening of that ring and the formation of a six-membered ring adjacent to another five-membered ring. Hydrogen abstraction reactions by methyl radicals on the zigzag and armchair edges of perylene are studied by density functional theory to explore various growth pathways that seem to be in line with experimental observations [87]. Notably, in the case of 3,4dimethyl-3,4-dihydroperylene, the first two reaction steps have no or only a very low reaction barrier. The final conclusion of this study is that a cascade of reactions is possible that leads to the growth of a graphene sheet on a graphite surface. Role of surface migration in the growth and structure of graphene layers is examined in [88].
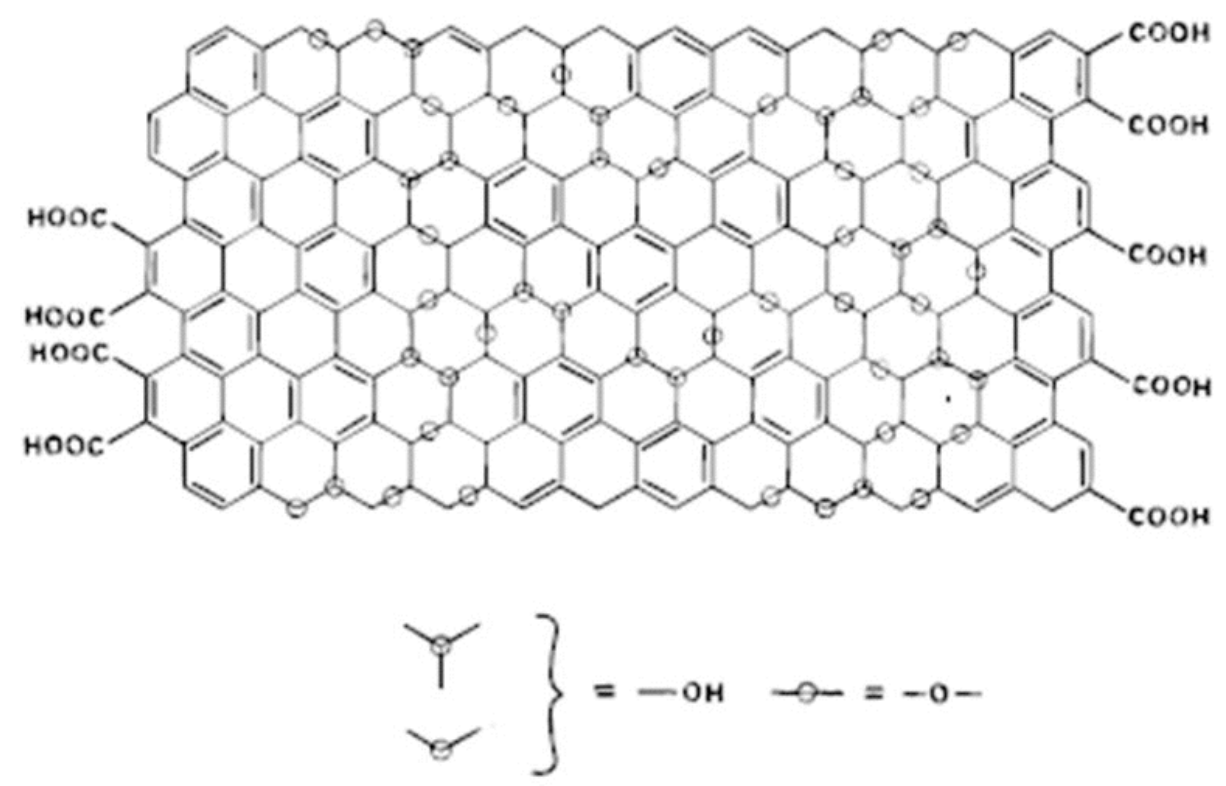

Fig. (8). Structural model for graphite oxide, borrowed from [82]. 


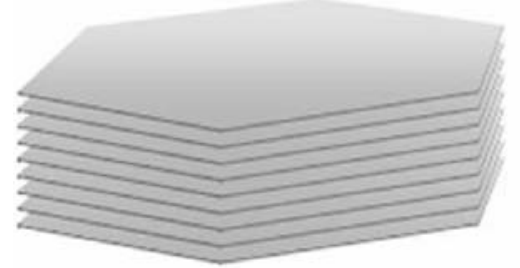

Graphite

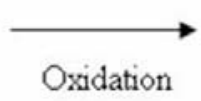

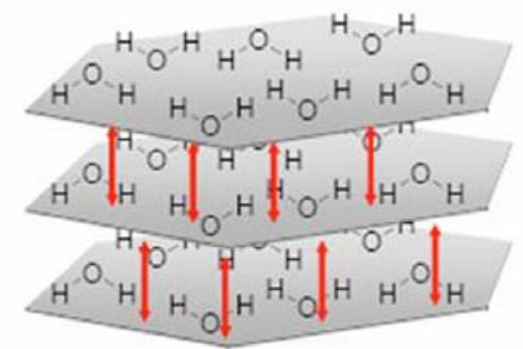

Graphite oxide

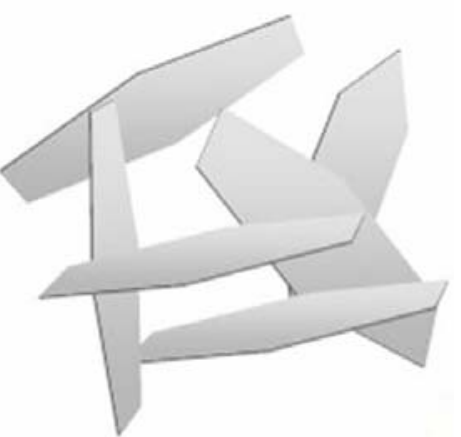

Thermally exfoliated graphite oxide

Fig. (9). Formation and exfoliation of graphite oxide, borrowed from [83].

Nano-graphene growth and texturing by Nd was investigated using pulsed laser ablation from a rotating graphite target operating both in vacuum $\left(\sim 10^{-5} \mathrm{~Pa}\right)$ and in He sustaining gas ( 10 Pa) [89]. As a result, thin carbon films grew on $\mathrm{Si}<100>$ substrates kept at temperatures from RT to $900{ }^{\circ} \mathrm{C}$ (Fig. 10). The preferential vertically oriented growth of graphene layers in vacuum and high temperature can be explained as a combined effect of different processes under a fast kinetic mode: thermal surface diffusion, in-plane growth of graphene sheets and line source direction of activated carbon species of the laser plume. The deposited samples are characterized by a different nucleation and growth process and a more complex structure.

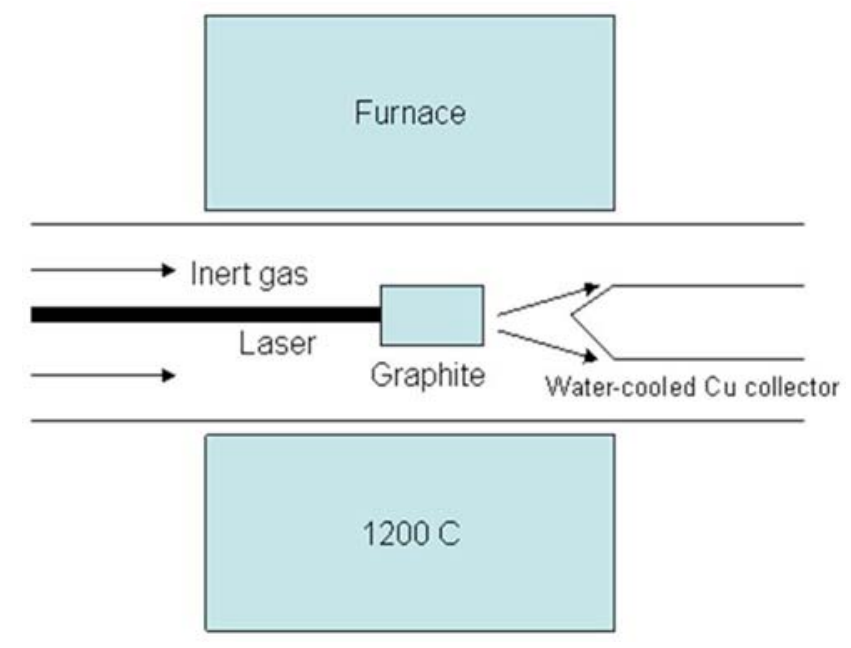

Fig. (10). Nano-graphene growth using laser ablation method.

\section{REACTIVITY}

A certain attention is given to the interaction of graphene and such simple inorganic molecules as hydrogen [90], oxygen, etc. Thus, quantum dynamics study of the LangmuirHinshelwood $\mathrm{H}+\mathrm{H}$ recombination mechanism and $\mathrm{H}_{2}$ formation on a graphene model surface is described in [91]. Two-dimensional semiconducting nanostructures based on single graphene sheets with lines of adsorbed hydrogen atoms were examined in [92]. It is shown that lines of ad- sorbed hydrogen pair atoms divide the graphene sheet into strips and form hydrogen-based superlattice structures (2HGSL). The formation of 2HG-SL changes the electronic properties of graphene from semimetal to semiconductor. In another research [93], the physisorption of a hydrogen molecule on planar and curved graphene clusters is examined. The repulsive nature of a $\mathrm{H}_{2}-\mathrm{H}_{2}$ interaction and the small dependence of physisorption energies on physisorption sites favor a close-packed structure for molecular hydrogen physisorption on a planar graphene. It is shown that $\mathrm{Li}$ doping enhances hydrogen physisorption on graphene [94]. Hydrogen molecules are physisorbed on pure graphene with binding energies about $80-90 \mathrm{meV} / \mathrm{molecule}$. However, the binding energies increase to $160-180 \mathrm{meV} /$ molecule for many adsorption configurations of the molecule near a $\mathrm{Li}$ atom in the doped systems. A charge-density analysis shows that the origin of the increase in binding energy is the electronic charge transfer from the $\mathrm{Li}$ atom to graphene and the nanotube. The mechanism and energy characteristics (activation energy and enthalpy) of interaction of linear and graphene carbon nanoparticles with an oxygen molecule are investigated by semiempirical PM3 method [95]. The oxidation activation energy depends on the structure of clusters and the interposition of the $\mathrm{O}_{2}$ molecule and a carbon cluster. Linear clusters are oxidized mainly to $\mathrm{CO}_{2}$; graphene clusters are oxidized to CO. Results of the reaction of ozone with milled graphite and different carbon black grades were based on the role played by fullerene-like carbon nanostructures, present in graphene sheets to explain the observed gasification rates and surface functionalization [96]. Theoretical study of sorption of carbon dioxide on the 4-ring graphene ("unmodified" or $\mathrm{N}-, \mathrm{O}-$, and $\mathrm{OH}$-substituted) structures possessing one completely unsaturated edge zigzag site is reported using the DFT (B3LYP/6-31G(d,p)) method [97].

Reactivity of graphene in relation with complex molecules is also studied. Thus, water can dissociate over defective sites in graphene following many possible reaction pathways, some of which have activation barriers lower than half the value for the dissociation of bulk water [98]. This reduction is caused by spin selection rules that allow the system to remain on the same spin surface throughout the reaction. The interaction of sulfuric acid with graphene is studied in [99] by density functional theory. The results show that 
there is protonation of the graphene sheet by the acid, in accordance with experimental results for $\mathrm{H}_{2} \mathrm{SO}_{4}$ adsorbed onto highly oriented pyrolytic graphite and for single-wall carbon nanotubes in concentrated sulfuric acid. Nevertheless the electronic structure of graphene is not heavily affected and its zero-band-gap semiconducting behavior is preserved.

Using first principles density functional theory methods, the authors of the investigation [100] shed light on the question how aryl groups attach to a graphene sheet. Thus, for the basal plane, isolated phenyl groups are predicted to be weakly bonded to the graphene sheet, even though a new single $\mathrm{C}-\mathrm{C}$ bond is formed between the phenyl group and the basal plane by converting a $\mathrm{sp}^{2}$-carbon in the graphene sheet to $\mathrm{sp}^{3}$. However, the interaction can be strengthened significantly with two phenyl groups attached to the para positions of the same six-membered ring to form a pair on the basal plane. The strongest bonding is found at the graphene edges.

Metal-graphene interactions are also being examined. Thus, density-functional calculations were done to examine the interface between graphene and a $\mathrm{Pt}_{13}$ or $\mathrm{Au}_{13}$ cluster [101]. Introducing a carbon vacancy into a graphene sheet enhanced the interaction between graphene and the metal clusters. Five- or seven-member rings introduced into the graphene also increased the stability of the interface. Lead(II) adsorption from an aqueous solution onto a graphene layer (C $\pi$ electrons) was investigated using activated carbon and charcoal [102]. The experimental results indicate that an acidic oxygen free graphene layer exhibits a basic character caused by $\mathrm{C} \pi$ electrons. For a Pd-metal graphite, having a layered structure, where each Pd sheet is sandwiched between adjacent graphene sheets, superconductivity and magnetic short-range order were studied [103].

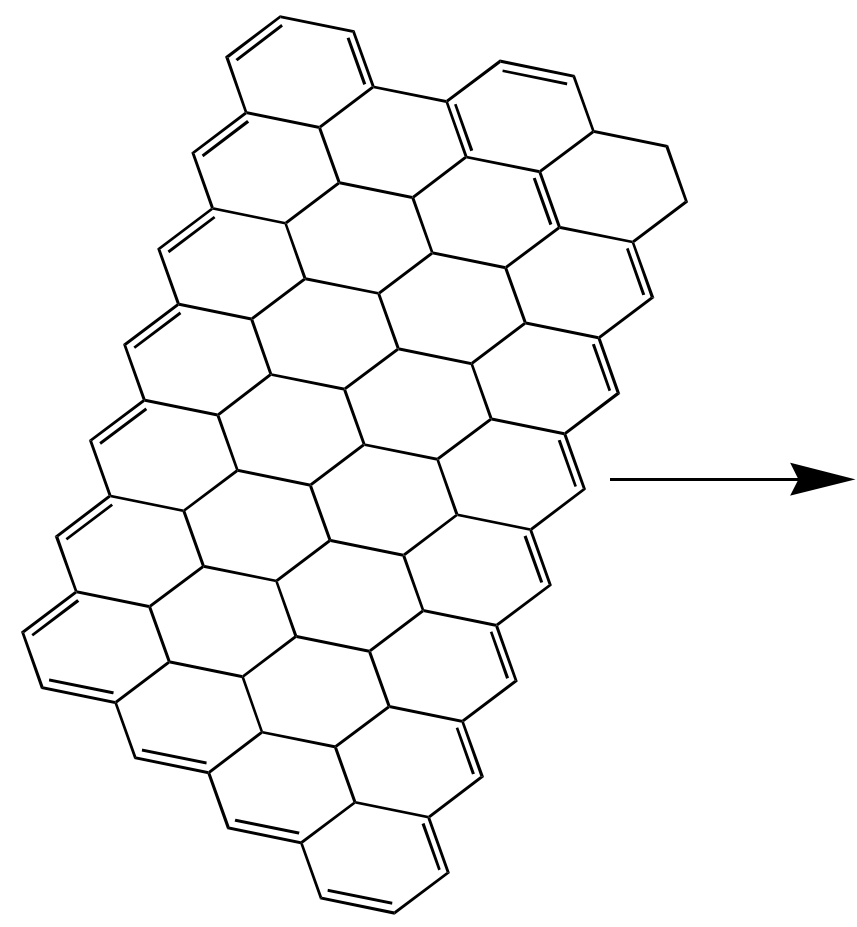

Graphene

\section{APPLICATIONS}

A series of investigations is dedicated to obtaining carbon nanotubes from graphenes. Depending on the concrete scheme of turning of graphite plane, formed nanotubes can possess metallic or semiconductor properties. The singlewalled nanotubes (SWNTs) are formed by folding graphene nanoribbons patterned on graphite films through adsorption of atoms of varying coverage, which introduces an external stress to drive the folding process (Fig. 11) [104]. The interaction of bare graphene nanoribbons (GNRs) was investigated by $a b$ initio density functional theory calculations with both the local density approximation (LDA) and the generalized gradient approximation (GGA) [105]. Remarkably, two bare 8-GNRs with zigzag-shaped edges are predicted to form an $(8,8)$ armchair single-wall SWCNT without any obvious activation barrier. A possible route to control the growth of specific types SWCNT via the interaction of GNRs is suggested. The use of graphene layer encapsulated catalytic metal particles for the growth of narrower multi-walled carbon nanotubes (MWCNTs) has been studied using plasmaenhanced chemical vapor deposition and conventional thermal CVD [106]. Ni-C or $\mathrm{Fe}-\mathrm{C}$ composite nanoclusters were fabricated using the dc arc discharge technique with metalgraphite composite. The results show that the diameters of the MWCNTs were reduced from 50-100 nm for a conventional Ni thin film-evaporated $\mathrm{Si}$ substrate to a minimum of roughly $2-4 \mathrm{~nm}$ in the present study. C-BN patterned singlewalled nanotubes synthesized by laser vaporization technique and a growth model is proposed [107]. The synthesis process consists of vaporizing, by a continuous $\mathrm{CO}_{2}$ laser, a target made of carbon and boron mixed with a $\mathrm{Co} / \mathrm{Ni}$ catalyst under $\mathrm{N}_{2}$ atmosphere. Boron and nitrogen co-segregate with

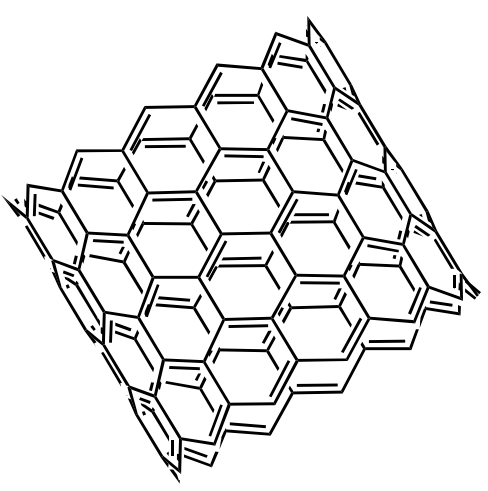

Single-walled carbon nanotube

Fig. (11). A simple route from a graphene sheet to a carbon nanotube. 
respect to carbon and form nanodomains within the hexagonal lattice of the graphene layer in a sequential manner.

Composite materials have been created on graphene basis [108]. Thus, transparent and electrically conductive composite silica films were fabricated on glass and hydrophilic $\mathrm{SiO}_{x} /$ silicon substrates by incorporation of individual graphene oxide sheets into silica sols followed by spin-coating, chemical reduction, and thermal curing [109]. Ultrathin epitaxial graphite films which show remarkable 2D electron gas (2DEG) behavior were produced. These films, composed of typically three graphene sheets, were grown by thermal decomposition on the (0001) surface of 6H-SiC [110]. Interaction with silicon carbide substrate leads to the opening of a semiconductor gap in epitaxial graphene [111]. This is an important first step towards bandgap engineering in this two-dimensional crystal, and its incorporation in electronic devices. Preparation and characterization of graphene oxide paper, a free-standing carbon-based membrane material made by flow-directed assembly of individual graphene oxide sheets, is reported in [112]. This new material outperforms many other paper-like materials in stiffness and strength. Its combination of macroscopic flexibility and stiffness is a result of a unique interlocking-tile arrangement of the nanoscale graphene oxide sheets.

Also, graphene is considered as one of the most promising materials for post silicon (carbon-based nanoelectronics) electronics, as it combines high electron mobility with atomic thickness [113, 114]. For example, applications of graphenes for transistor production is reported in [115-117]. The transistors show a hole and electron mobility of 3735 and $795 \mathrm{~cm}^{2} / \mathrm{V}$-s, respectively, and a maximum drive-current of $1.7 \mathrm{~mA} / \mu \mathrm{m}$ (at $V_{\mathrm{DS}}=1 \mathrm{~V}$ ), which are among the highest reported for room temperature. Intrinsic current-voltage characteristics of graphene nanoribbon transistors are examined in [118].

Nanodevices $[119,120]$ are the most perspective present and future application area for graphenes. Thus, graphenes can be potentially used in digital memory devices [121] or as building blocks for novel optoelectronic devices [122]. Microfabrication of graphene devices currently relies on the fact that graphene crystallites can be visualized using optical microscopy if prepared on top of $\mathrm{Si}$ wafers with a certain thickness of $\mathrm{SiO}_{2}$ [123]. Graphene's visibility depends strongly on both thickness of $\mathrm{SiO}_{2}$ and light wavelength. It was found that by using monochromatic illumination, graphene can be isolated for any $\mathrm{SiO}_{2}$ thickness, albeit $300 \mathrm{~nm}$ (the current standard) and, especially, $\sim 100 \mathrm{~nm}$ are most suitable for its visual detection.

Transparent, conductive, and ultrathin graphene films are demonstrated as an alternative to the ubiquitously employed metal oxides window electrodes for solid-state dyesensitized solar cells [124]. These graphene films are fabricated from exfoliated graphite oxide, followed by thermal reduction. The obtained films exhibit a high conductivity of $550 \mathrm{~S} / \mathrm{cm}$ and a transparency of more than $70 \%$ over $1000-$ $3000 \mathrm{~nm}$.

Carbon-based 3-D solid structures, called covalently bonded graphenes (CBGs), were investigated to elucidate hydrogen storage characteristics [125]. Using the density functional method and the MØller-Plesset perturbation method, it is shown that $\mathrm{H}_{2}$ molecular binding in the CBGs is stronger than that on an isolated graphene with an increase of 20 to $\sim 150 \%$ in binding energy, which is very promising for storage at ambient conditions. Graphene nanostructures serve as tunable storage media for molecular hydrogen, because they are light-weight, cheap, chemically inert, and environmentally benign [126].

The possibility of chemical doping and related excellent chemical sensor properties of graphene have been experimentally demonstrated [127]. Thus, graphene sheets can be effective adsorbents and sensors for dioxin in the presence of calcium atoms [128]. This is due to a cooperative formation of sandwich complexes of graphene sheet or $(5,5)$ CNT through the interaction $\pi$-Ca- $\pi$ with the total binding energy of more than $3 \mathrm{eV}$. The first joint experimental and theoretical investigation of adsorbate-induced doping of graphene is presented in [129] with the $\mathrm{NO}_{2}$ system. It is shown that the single, open shell $\mathrm{NO}_{2}$ molecule is found to be a strong acceptor, whereas its closed shell dimer $\mathrm{N}_{2} \mathrm{O}_{4}$ causes only weak doping. This effect is pronounced by graphene's peculiar density of states (DOS), which provides an ideal situation for model studies of doping effects in semiconductors.

\section{CONCLUSIONS}

Graphene, the youngest [130] allotropic form of carbon, can be considered as a promising leader in future publications among other carbon forms. Efforts on carbon allotropes in $1990^{\text {th }}-2008$ years have been devoted to fullerenes, SWCNTs and MWCNTs, enormous number of publications is dedicated to their obtaining and applications. In case of graphene, at present we observe all attributes of an approaching boom due to its unique properties and possible applications [131-134]. At the same time, meanwhile an interest of physicians and technologists to this material is obvious, an interest of chemists [11] is below of the expected, probably due to absence of a well-established industrial method for graphene production. We suppose that, in near future, the most important contribution of chemists could be the elaboration of a cheap and easy wet-chemical synthetic method for obtaining graphene, as well as chemical modification by insertion of various organic functional groups into its structure in order to manipulate properties of this valuable material.

\section{FUTURE OUTLOOK}

As it was noted by Geim and Novoselov [2], "at this time, no review can possibly be complete". A dramatic increase of experimental publications and patents is expected next years, dedicated to the optimization of synthetic methods for graphene and its applications in various technological areas (composite materials, batteries, gas sensors, field emitters, etc.).

\section{REFERENCES}

[1] Katsnelson, M.I.; Novoselov, K.S. Solid State Commun., 2007, $143(1), 3$.

[2] Geim, A.K.; Novoselov, K.S. Nat. Mater, 2007, 6(3), 183.

[3] Gogotsi, Yu. (Ed.). Carbon Nanomaterials. CRC, 2006, p. 344.

[4] Jorio, A.; Dresselhaus, M.S.; Dresselhaus, G.; Gogotsi, Yu. (Edits.). Carbon Nanotubes: Advanced Topics in the Synthesis, Structure, Properties and Applications. Springer; 1 edition, 2008, p. 744. 
[5] Haug, R. (Edit.). Advances in Solid State Physics. Springer; 1 edition, Vol. 47, 2008, p. 363.

[6] Bharat B. B. (Ed.). Springer Handbook of Nanotechnology. Springer; 1 edition, 2008, p. 363.

[7] Van Noorden, R. Nature, 2006, 442, 228.

[8] Müller, S.; Müllen, K. Philosophical Transactions of the Royal Society A: Math. Phys. Eng. Sci., 2007, 365(1855), 1453.

[9] Ando, T. Physica E: Low-dimensional Systems and Nanostructures, 2007, 40(2), 213.

[10] Aida, Takuzo; Fukushima, Takanori. Philosophical Transactions of the Royal Society A: Mathematical, Physical and Engineering Sciences, 2007, 365(1855), 1539.

[11] Wu, J.; Pisula, W.; Mullen, K. Chem. Rev., 2007, 107, 718.

[12] Gruner, G.; Hu, L.; Hecht, D. Graphene film as transparent and electrically conducting material. U.S. patent 20070284557, 2007. http://www.freepatentsonline.com/20070284557.html.

[13] Prud'homme, R.K.; Ozbas, B.; Aksay, I.A.; Register, R.A.; Adamson, D.H. Functional Graphene - Rubber Nanocomposties. U.S. Patent Application Filed - Invention \# 07-2323-1, 2006.

[14] Jang, B.Z. Highly conductive nano-scaled graphene plate nanocomposites and products. US Patent 20070158618, 2007. http://www.freshpatents.com/Bor-Z-Jang-cndirb.php.

[15] Abanin, D.A.; Novoselov, K.S.; Zeitler, U.; Lee, P.A.; Geim, A.K.; Levitov, L.S. Phys. Rev. Lett., 2007, 98(19), 196806.

[16] Schedin, F.; Geim, A.K.; Morozov, S.V.; Hill, E.W.; Blake, P.; Katsnelson, M.I.; Novoselov, K.S. Nat. Mater., 2007, 6(9), 652.

[17] Meyer, J.C.; Geim, A.K.; Katsnelson, M.I.; Novoselov, K.S.; Obergfell, D.; Roth, S.; Girit, C.; Zettl, A. Solid State Comm., 2007, 143(1), 101 .

[18] Novoselov, K.S.; Jiang, Z.; Zhang, Y.; Morozov, S.V.; Stormer, H.L.; Zeitler, U.; Maan, J.C.; Boebinger, G.S.; Kim, P.; Geim, A.K. Science, 2007, 315(5817), 1379.

[19] Pisana, S.; Lazzeri, M.; Casiraghi, C.; Novoselov, K.S.; Geim, A.K.; Ferrari, A.C.; Mauri, F. Nat. Mater. 2007, 6(3), 198.

[20] van den Brink, J. Nat. Nanotechnol., 2007, 2(4), 199.

[21] Hashimoto, A.; Suenaga, K.; Gloter, A.; Urita, K.; Iijima, S. Nature, 2004, 430(7002), 870.

[22] Meyer, J.C.; Geim, A.K.; Katsnelson, M.I.; Novoselov, K.S.; Booth, T.J.; Roth, S. Nature, 2007, 446(7131), 60.

[23] Lin, C.-T.; Lee, C.-Y.; Chiu, H.-T.; Chin, T.-S. Langmuir, 2007, 23(26); 12806

[24] Chen, Y.; Lu, J.; Gao, Z. J. Phys. Chem. C., 2007, 111(4), 1625.

[25] Peralta-Inga, Z.; Murray, J.S.; Edward Grice, M.; Boyd, S.; O'Connor, C.J.; Politzer, P. J. Mol. Struct.: THEOCHEM, 2001, 549(1), 147.

[26] Image gallery - graphite and graphene. http://www.ewels.info/img/ science/graphite/index.html (accessed January 26, 2008).

[27] Shigeo, H.; Takuya, G.; Masahiro, F.; Toru, A.; Tadahiro, Y.; Yoshio, M. Appl. Phys. Lett., 2004, 84, 2403.

[28] Ni, Z.H.; Wang, H.M.; Kasim, J.; Fan, H.M.; Yu, T.; Wu, Y.H.; Feng, Y.P.; Shen, Z.X. Nano Lett., 2007, 7(9), 2758.

[29] Casiraghi, C.; Hartschuh, A.; Lidorikis, E.; Qian, H.; Harutyunyan, H.; Gokus, T.; Novoselov, K.S.; Ferrari, A.C. Nano Lett., 2007, 7(9), 2711

[30] Grimme, S.; Muck-Lichtenfeld, C.; Antony, J. J. Phys. Chem. C., 2007, 111(30), 11199.

[31] Ishigami, M.; Chen, J. H.; Cullen, W. G.; Fuhrer, M. S.; Williams, E. D. Nano Lett., 2007, 7(6), 1643.

[32] Sitenko, Yu.A., Vlasii, N.D. Nucl. Phys. Sect. B, 2007, 787(3), 241.

[33] Barone, V.; Hod, O.; Scuseria, G.E. Nano Lett., 2006, 6(12), 2748.

[34] Cortijo, A.; Vozmediano, M.A.H. Europhysics Lett., 2007, 77(4), 47002.

[35] Lopez-Urias, F.; Rodriguez-Manzo, J.A.; Munoz-Sandoval, E.; Terrones, M.; Terrones, H. Opt. Mater., 2006, 29(1), 110.

[36] Katsnelson, M.I. Mater. Today, 2007, 10(1), 20.

[37] Graphene makes movement easy for electrons. http://www. physorg.com/news119030362.html, posted January 08, 2008.

[38] McCann, E.; Abergel, D.S.L.; Fal'ko, V.I. Solid State Commun., 2007, 143(1), 110 .

[39] Hod, O.; Barone, V.; Peralta, J.E.; Scuseria, G.E. Nano Lett., 2007, 7(8), 2295.

[40] Gomez-Navarro, C.; Weitz, R.T.; Bittner, A.M.; Scolari, M.; Mews, A.; Burghard, M.; Kern, K. Nano Lett., 2007; 7(11), 3499.

[41] Wang, W.L.; Meng, S.; Kaxiras, E. Nano Lett., 2008, 8(1); 241.

[42] Jiang, De-en; Sumpter, B.G.; Dai, S. J. Chem. Phys., 2007, 127(12), 124703.
[43] Fernández-Rossier, J.; Palacios, J. J. Phys. Rev. Lett., 2007, 99, 177204.

[44] Niyogi, S.; Bekyarova, E.; Itkis, M.E.; McWilliams, J.L.; Hamon, M.A.; Haddon, R.C. J. Am. Chem. Soc., 2006, 128(24), 7720.

[45] Worsley, K.A.; Ramesh, P.; Mandal, S.K.; Niyogi, S.; Itkis, M.E.; Haddon, R.C. Chem. Phys. Lett., 2007, 445(1), 51

[46] Yang, L.; Cohen, M.L.; Louie, S.G. Nano Lett., 2007, 7(10), 3112.

[47] Jung, I.; Pelton, M.; Piner, R.; Dikin, D.A.; Stankovich, S.; Watcharotone, S.; Hausner, M.; Ruoff, R.S. Nano Lett., 2007, 7(12), 3569 .

[48] Graf, D.; Molitor, F.; Ensslin, K.; Stampfer, C.; Jungen, A.; Hierold, C.; Wirtz, L. Nano Lett., 2007, 7(2), 238.

[49] Calizo, I.; Miao, F.; Bao, W.; Lau, C.N.; Balandin, A.A. Appl. Phys. Lett., 2007, 91, 071913.

[50] Calizo, I.; Balandin, A.A.; Bao, W.; Miao, F.; Lau, C.N. Nano Lett., 2007, 7(9), 2645.

[51] Calizo, I.; Bao, W.; Miao, F.; Chun Ning Lau; Balandin, A.A. Appl. Phys. Lett., 2007, 91, 201904.

[52] Guo, J.; Yoon, Y.; Ouyang, Y. Nano Lett., 2007, 7(7), 1935.

[53] Son, Y.-W.; Cohen, M.L.; Louie, S.G. Phys. Rev. Lett., 2006, 97, 216803.

[54] Son, Y.-W.; Cohen, M.L.; Louie, S.G. Nature, 2006, 444, 347.

[55] Yang, L.; Park, C.H.; Son, Y.-W.; Cohen, M.L.; Louie, S.G. Phys. Rev. Lett., 2007, 99, 186801

[56] Martins, T.B.; Miwa, R.H.; da Silva, A.J.R.; Fazzio, A. Phys. Rev. Lett., 2007, 98(19), 196803.

[57] Shemella, P.; Zhang, Y.; Mailman, M.; Ajayan, P.M.; Nayak, S.K. Appl. Phys. Lett., 2007, 91, 042101.

[58] Liang, G.; Neophytou, N.; Lundstrom, M.S.; Nikonov, D.E. J. Appl. Phys., 2007, 102, 054307.

[59] Jiang, De-en; Sumpter, B.G.; Dai, S. J. Chem. Phys., 2007, 126(13), 134701

[60] Ryzhii V. Jpn. J. Appl. Phys., 2006, 45, L923. doi:10.1143/JJAP.45.L923.

[61] Ryzhii, V.; Satou, A.; Otsuji, T. J. Appl. Phys., 2007, 101, 024509. doi:10.1063/1.2426904.

[62] Novoselov, K.; Jiang, S.D.; Schedin, F.; Booth, T.J.; Khotkevich, V.V.; Morozov, S.V.; Geim, A.K. Proc. Natl. Acad. Sci. USA, 2005, 102, 10451. doi:10.1073/pnas.0502848102.

[63] Somani, P.R.; Somani, S.P.; Umeno, M. Chem. Phys. Lett., 2006 430(1), 56-59.

[64] Rollings, E.; Gweon, G.H.; Zhou, S.Y.; Mun, B.S.; McChesney, J.L.; Hussain, B.S.; Fedorov, A.V.; First, W.A. de Heer; Lanzara, A. J. Phys. Chem. Sol., 2006, 67(9), 2172.

[65] Jang, Bor Z.; Huang, Wen C. Nano-scaled graphene plates. U.S Patent 7071258, 2006. http://www.freepatentsonline.com/7071258. html.

[66] Ohta, T.; Bostwick, A.; Seyller, T.; Horn, K.; Rotenberg, E. Science, 2006, 313(5789), 951-954.

[67] de Heer, W.A.; Berger, C.; Wu, X.; First, P.N.; Conrad, E.H.; Li, T.; Sprinkle, M.; Hass, J.; Sadowski, M.L.; Potemski, M.; Martinez, G. Solid State Commun., 2007, 143(1), 92.

[68] Riedl, C.; Starke, U. Phys. Rev. B, 2007, 76, 245406.

[69] Hass, J.; Feng, R.; Li, T.; Li, X.; Zong, Z.; de Heer, W.A.; First, P.N.; Conrad, E.H.; Jeffrey, C.A.; Berger, C. Appl. Phys. Lett., 2006, 89, 143106.

[70] Berger, C.; Song, Z.; Li, X.; Wu, X.; Brown, N.; Naud, C.; Mayou, D.; Li, T.; Hass, J.; Marchenkov, A.N.; Conrad, E.H.; First, P.N.; de Heer, W.A. Science, 2006, 312, 1191. doi:10.1126/science. 1125925

[71] Osvath, Z.; Darabont, Al.; Nemes-Incze, P.; Horvath, E.; Horvath, Z.E.; Biro, L.P. Carbon, 2007, 45(15), 3022.

[72] Zhu, Z.; Su, D.; Weinberg, G.; Schlogl, R. Nano Lett., 2004, 4(11), 2255.

[73] Stankovich, S.; Dikin, D.A.; Piner, R.D.; Kohlhaas, K.A.; Kleinhammes, A.; Jia, Y.; Wu, Y.; SonBinh T. Nguyen; Ruoff, R.S. Carbon, 2007, 45(7), 1558.

[74] Gregg, D.J.; Bothe, E.; Höfer, P.; Passaniti, P.; Draper, S.M. Inorg. Chem., 2005, 44(16), 5654.

[75] Draper, M. S.; Gregg, D. J.; Schofield, E. R.; Browne, W. R.; Duati, M.; Vos, J. G.; Passaniti, P. J. Am. Chem. Soc. 2004, 126, 8694.

[76] Gilje, S.; Han, S.; Wang, M.; Wang, K.L.; Kaner, R.B. Nano Lett., 2007, 7(11), 3394

[77] McAllister, M.J.; Li, J.-L.; Adamson, D.H.; Schniepp, H.C.; Abdala, A.A.; Liu, J.; Herrera-Alonso, M.; Milius, D.L.; Car, R.; Prud'homme, R.K.; Aksay, I.A. Chem. Mater., 2007, 19(18), 4396. 
[78] Schniepp, H.C.; Li, J.-L.; McAllister, M.J.; Sai, H.; HerreraAlonso, M.; Adamson, D.H.; Prud'homme, R. K.; Car, R.; Saville, D.A.; Aksay, I.A. J. Phys. Chem. B., 2006, 110(17), 8535.

[79] Stankovich, S.; Piner, R.D.; Nguyen, S.T.; Ruoff, R.S. Carbon, 2006, 44(15), 3342.

[80] Viculis, L.M.; Mack, J.J.; Kaner, R.B. Science, 2003, 299, 1361.

[81] Young-Woo Son. Physics of graphene and graphene nanoribbons. http://icpr.or.kr/file/vod/2007/yonsei/20071205.pdf. Posted on December 05, 2007.

[82] Lerf, A.; He, H.; Forster, M.; Klinowski, J. J. Phys. Chem. B., 1998, $102,4477$.

[83] Aksay, I.A. Developing fundamental developing fundamental insights pertinent to the design and processing of multifunctional nanocomposites. http://www.wtec.org/nb-france-us/aksay_i/aksaymodified.pdf. Posted on March 02, 2006.

[84] Sidorov, A.N.; Yazdanpanah, M.M.; Jalilian, R.; Ouseph, P.J.; Cohn, R.W.; Sumanasekera, G.U. Nanotechnology, 2007, 18(13), 135301.

[85] Northrop, B.H.; Norton, J.E.; Houk, K.N. J. Am. Chem. Soc., 2007, $129(20), 6536$.

[86] Whitesides, R.; Kollias, A.C.; Domin, D.; Lester, W.A.; Frenklach, M. Proc. Combust. Instit., 2007, $31(1), 539$.

[87] Carissan, Yannick; Klopper, Wim. Eur. J. Chem. Phys. Phys. Chem., 2006, 7(8), 1770.

[88] Frenklach, M.; Ping, J. Carbon, 2004, 42(7), 1209.

[89] Cappelli, E.; Orlando, S.; Morandi, V.; Servidori, M.; Scilletta, C. J. Phys.: Conference Series, 2007, 59(1), 616.

[90] Miura, Y.; Kasai, H.; Diño, W.; Nakanishi, H.; Sugimoto, T. J. Appl. Phys., 2003, 93, 3395.

[91] Kerkeni, B.; Clary, D.C. Chem. Phys., 2007, 338(1), 1.

[92] Chernozatonskii, L.A.; Sorokin, P.B. Appl. Phys. Lett., 2007, 91, 183103.

[93] Okamoto, Y.; Miyamoto, Y. J. Phys. Chem. B., 2001, 105(17), 3470.

[94] Cabria, I.; López, M.J.; Alonso, J.A. J. Chem. Phys., 2005, 123, 204721.

[95] Zavodinsky, V.G.; Mikhailenko, E.A. Comput. Mater. Sci., 2006, $36(1), 159$.

[96] Cataldo, F. J. Nanosci. Nanotechnool., 2007, 7(4-5), 1446.

[97] Gauden, P.A.; Wisniewski, M. Appl. Surface Sci., 2007, 253(13), 5726.

[98] Kostov, M.K.; Santiso, E.E.; George, A.M.; Gubbins, K.E.; Nardelli, M.B. Phys. Rev. Lett., 2005, 95(13), 136105.

[99] Cordero, N.A.; Alonso, J.A. Nanotechnology, 2007, 18(48), 485705.

[100] Jiang, D.-E.; Sumpter, B. G.; Dai, S. J. Phys. Chem. B., 2006, 110(47), 23628.

[101] Okamoto, Y. Chem. Phys. Lett., 2006, 420(4), 382.

[102] Machida, M.; Mochimaru, T.; Tatsumoto, H. Carbon, 2006, 44(13), 2681

[103] Masatsugu, Suzuki; Itsuko S Suzuki; Jürgen, Walter. J. Phys.: Condens. Matter., 2004, 16(6), 903.

[104] Yu, Decai; Liu, Feng. Nano Lett., 2007, 7(10), 3046.

[105] Du, A.J.; Smith, S.C.; Lu, G.Q. Nano Lett., 2007, 7(11), 3349.

[106] Nagatsu, M.; Yoshida, T.; Mesko, M.; Ogino, A.; Matsuda, T.; Tanaka, T.; Tatsuoka, H.; Murakami, K. Carbon, 2006, 44(15), 3336.

[107] Enouz, Shaïma; Stéphan, Odile; Cochon, Jean-Lou; Colliex, Christian; Loiseau, Annick. Nano Lett., 2007, 7(7), 1856.
[108] Stankovich, S.; Dikin, D.A.; Dommett, G.H.B.; Kohlhaas, K.M.; Zimney, E.J.; Stach, E.A.; Piner, R.D.; Nguyen, S.B.T.; Ruoff, R.S. Nature, 2006, 442, 282.

[109] Watcharotone, S.; Dikin, D.A.; Stankovich, S.; Piner, R.; Jung, I.; Dommett, G.H.B.; Evmenenko, G.; Wu, S.-E.; Chen, S.-F.; Liu, C.P.; Nguyen, S.T.; Ruoff, R.S. Nano Lett., 2007, 7(7), 1888.

[110] Berger, C.; Song, Z.; Li, T.; Li, X.; Ogbazghi, A.Y.; Feng, R.; Dai, Z.; Marchenkov, A.N.; Conrad, E.H.; First, P.N.; de Heer, W.A. J. Phys. Chem. B., 2004, 108(52), 19912.

[111] Novoselov, K. Nat. Mater., 2007, 6(10), 720.

[112] Dikin, D.A.; Stankovich, S.; Zimney, E.J.; Piner, R.D.; Dommett, G.H.B.; Evmenenko, G.; Nguyen, S.B.T.; Ruoff, R.S. Nature, 2007, 448(7152), 457.

[113] Novoselov, K.S.; Geim, A.K.; Morozov, S.V.; Jiang, D.; Zhang, Y.; Dubonos, S.V.; Grigorieva, I.V.; Firsov, A.A. Science, 2004, 306, 666 .

[114] Areshkin, D.A.; White, C.T. Nano Lett., 2007, 7(11); 3253.

[115] Liang, X.; Fu, Z.; Chou, S.Y. Nano Lett., 2007, 7(12), 3840.

[116] Semenov, Y.G.; Kim, K.W.; Zavada, J.M. Appl. Phys. Lett., 2007, $91,153105$.

[117] Chen, Z.; Lin, Y.-M.; Rooks, M.J.; Avouris, P. Phys. E: Lowdimension. Syst. Nanostruct., 2007, 40(2), 228.

[118] Yan, Q.; Huang, B.; Yu, J.; Zheng, F.; Zang, J.; Wu, J.; Gu, B.-L.; Liu, F.; Duan, W. Nano Lett., 2007, 7(6), 1469.

[119] Jayasekera, T.; Mintmire, J.W. Nanotechnology, 2007, 18(42), 424033.

[120] Staley, N.; Wang, H.; Puls, C.; Forster, J.; Jackson, T.N.; McCarthy, K.; Clouser, B.; Liu, Y. Appl. Phys. Lett., 2007, 90, 143518.

[121] Gunlycke, D.; Areshkin, D.A.; Li, J.; Mintmire, J.W.; White, C.T Nano Lett., 2007, 7(12), 3608.

[122] Roddaro, S.; Pingue, P.; Piazza, V.; Pellegrini, V.; Beltram, F. Nano Lett., 2007, 7(9), 2707.

[123] Blake, P.; Hill, E.W.; Castro Neto, A.H.; Novoselov, K.S.; Jiang, D.; Yang, R.; Booth, T.J.; Geim, A.K. Appl. Phys. Lett., 2007, 91, 063124.

[124] Wang, X.; Zhi, L.; Mullen, K. Nano Lett., 2008, 8(1); 323.

[125] Park, N.; Hong, S.; Kim, G.; Jhi, S.-H. J. Am. Chem. Soc., 2007 , 129(29), 8999.

[126] Patchkovskii, S.; Tse, J.S.; Yurchenko, S.N.; Zhechkov, L.; Heine, T.; Seifert, G. Proc. Nat. Acad. Sci. USA, 2005, 102(30), 10439.

[127] Schedin, F.; Geim, A.K.; Morozov, S.V.; Hill, E.W.; Blake, P.; Katsnelson, M.I.; Novoselov, K.S. Nat. Mater., 2007, 6, 652.

[128] Kang, H.S. J. Am. Chem. Soc., 2005, 127(27), 9839.

[129] Wehling, T.O.; Novoselov, K.S.; Morozov, S.V.; Vdovin, E.E.; Katsnelson, M.I.; Geim, A.K.; Lichtenstein, A.I. Nano Lett., 2008, 8(1), 173.

[130] Novoselov, K.S.; Geim, A.K.; Morozov, S.V.; Jiang, D.; Zhang, Y.; Dubonos, S.V.; Grigorieva, I.V.; Firsov, A.A. Science, 2004, 306, 666 .

[131] Xiaolin Li; Xinran Wang; Li Zhang; Sangwon Lee; Hongjie Dai. Science, 2008, DOI: 10.1126/science.1150878.

[132] Wilson, M. Phys. Today, 2006, 59(1), 21-23.

[133] Castro Neto, A.; Guinea, F.; Peres, N.M. Phys. World, 2006, 19 , 33.

[134] Geim, A.K.; MacDonald, A.H. Phys. Today, 2007, 60, 35-41. 